\title{
BMJ Open Correlation between patient and visitor violence and workload among public healthcare workers in China: a cross- sectional study
}

\author{
Ju Huang (D) , ${ }^{1}$ Min Zhang, ${ }^{2}$ Xin Liu ${ }^{3}$
}

To cite: Huang J, Zhang M, Liu X. Correlation between patient and visitor violence and workload among public healthcare workers in China: a cross-sectional study. BMJ Open 2020;10:e034605. doi:10.1136/ bmjopen-2019-034605

- Prepublication history for this paper is available online. To view these files, please visit the journal online (http://dx.doi. org/10.1136/bmjopen-2019034605).

Received 29 September 2019 Revised 01 April 2020 Accepted 06 April 2020

A) Check for updates

(C) Author(s) (or their employer(s)) 2020. Re-use permitted under CC BY-NC. No commercial re-use. See rights and permissions. Published by BMJ.

${ }^{1}$ Institute of Medical Information, Chinese Academy of Medical Sciences and Peking Union Medical College, Beijing, China ${ }^{2}$ School of Public Health, Chinese Academy of Medical Sciences and Peking Union Medical College, Beijing, China ${ }^{3}$ Institute of Evidence Law and Forensic Science, China University of Political Science and Law, Beijing, China

Correspondence to Dr Min Zhang; minzhang928@vip.sina.com; zhangmin@sph.pumc.edu.cn

\section{ABSTRACT}

Objectives We studied the characteristics of patient and visitor violence (PVV) and the workload of doctors and nurses, and identified the correlation between the incidence of PVV and healthcare worker (HCW) workload in China.

Design Cross-sectional study.

Setting 288 public health institutions in a city in northern China.

Participants Data on 87998 HCWs were extracted from the 2015 database of the Medical Quality and Safety Notification System.

Measures The data included characteristics of the healthcare institution, types of services provided, information about each complaint and reported PVV incidents by hospital level. Pearson correlation analysis and multiple linear regression modelling were used to identify the correlation between the incidence of PVV and HCW workload.

Results Three types of institutions were identified as being at particularly high risk for PVV: tertiary hospitals, specialised hospitals and institutions in a downtown district. Incidence rates of PVV at tertiary hospitals, specialised hospitals and institutions in a downtown district were $16.6 \%, 17.6 \%$ and $22.8 \%$, respectively. All three types of institutions had a high inpatient workload (admissions per doctor per day): $0.15,0.17$ and 0.12 , respectively. After controlling for scale, type and location, it was found that the overall incidence rate of PVV increased with increasing outpatient workload $(\beta=0.236, p<0.01)$. Conclusions PV poses a significant challenge to public health institutions in China, and the high workload of HCWs likely contributes to higher risk of PV. Prevention and intervention of PVV may be targeted to HCWs at specific institutions. The patient complaint notification system needs improvement and could be, for example, a better source of PVV information for future interventions.

\section{INTRODUCTION}

Violence against health personnel is a widespread problem that may affect more than half of healthcare workers (HCW). ${ }^{1}$ Findings of a recent German study indicate that the prevalence of physical and verbal violence has increased and has become part of the daily working life of many HCWs. ${ }^{2}$ Patient
Strengths and limitations of this study

- This is the first Chinese study to examine patient and visitor violence (PVV) incidence rates in terms of criminal violence using big data.

- Multiple linear regression modelling was used to determine the correlation between the incidence of PWV and healthcare worker workload.

- This study had several limitations related to data availability and quality.

- Domestic data on violence in China are defined differently from international data.

- The findings provide useful evidence to guide future PVV interventions among Chinese public health institutions.

and visitor violence (PVV) can lead to physical injury, psychological harm (eg, fear and turnover intention), ${ }^{3}{ }^{4}$ physical disability and death among HCWs. ${ }^{5}$ The International Labour Office (ILO), the International Council of Nurses (ICN), the WHO and Public Services International (PSI) have suggested in the training manual of the Framework Guidelines for Addressing Workplace Violence in the Health Sector ${ }^{6}$ that this violence also impacts the delivery of healthcare services by gradually reducing the services available to the general population and by increasing costs. Sources of violence in the health sector can be internal (eg, violence that takes place between coworkers or between staff members and managers) or external (eg, violence from patients and visitors towards staff). ${ }^{1}$ PVV towards HCWs is the most common and serious form of violence in the workplace in both low and middle-income countries and developed countries. ${ }^{7-10}$ HCWs in China are often victims of PVV. ${ }^{11-17}$ Reports indicate that there were 155 incidents of serious violence (ie, injury or murder) against HCWs in 2014, and the number of prosecuted perpetrators of violence against HCWs in China was 3308, 
4508 and 3202 in 2016, 2017 and 2018, respectively. ${ }^{18}$ According to recent studies conducted in China that used the same international instrument tools developed by the ILO, ICN, WHO and PSI to measure workplace violence, the incidence of physical and psychological workplace violence against medical workers varied depending on work context; work type; and hospital tier, size, location and culture. Incidence rates of physical and psychological workplace violence ranged from $7 \%$ to $11 \%$ and $47 \%$ to $72 \%$, respectively. ${ }^{13}{ }^{17-21}$

Ending workplace violence and harassment requires international political commitment, ${ }^{22}$ and such a commitment was proposed at the 2019 ILO Violence and Harassment Convention (No 190). ${ }^{23}$ In China, a three-stage strategy and action plan that includes prosecution of criminal offenders has been implemented. The first stage was to fight against extreme criminal violence (20142016). The second stage was to develop a comprehensive system against violence (2016-2017). The third and final stage was to establish a governmental joint punishment system for those who attack medical staff (since 2018). ${ }^{18}$ In the second stage, a national campaign entitled Security Hospital Establishment was launched by the central government for secondary and tertiary hospitals and has been in place since $2016 .{ }^{24}$ In addition, the PVV situation in China has received much attention from the ILO and WHO. The ILO/WHO technical tool HealthWISE can be used to combat workplace violence. ${ }^{25}$

The factors associated with violence against HCWs have been studied worldwide for years. Previous studies have examined the characteristics of perpetrators and victims, staff training, interpersonal relationships, and department/unit and organisational management. HCW burnout, depression and PVV appear to be linked. ${ }^{46}$ Factors such as prolonged waiting times and lack of doctor availability have been found to be strongly correlated with workload among HCWs. ${ }^{27-33}$ A recent study on doctor workload and medical disputes at a tertiary teaching hospital in China showed that the Chinese doctor's workload is rapidly increasing, and the increases have been associated with medical disputes. ${ }^{34}$ However, there have been few studies that have focused on the workload of HCWs, and, to our knowledge, none have demonstrated a quantitative correlation between PVV and workload among HCWs.

Since 2002, patient complaint management has been a major aspect of healthcare quality control in Chinese public health institutions (PHIs). ${ }^{35}$ Therefore, in a large city of north China (hereafter referred to as 'the City'), PHIs are required to use the Medical Quality and Safety Notification System (hereafter referred as 'the Notification System'), which was developed by the local health authority for the purpose of surveillance. The Notification System is used for patient-reported complaints, including incidences of violence.

This study extracted and analysed data from the Notification System in order to accomplish three aims: (1) to determine the incidence rate of PVV and the characteristics of workload among HCWs, (2) to examine the correlation between PVV and workload among HCWs, and (3) to develop recommendations for PVV prevention and control for China and other countries based on this new empirical evidence.

\section{METHODS}

\section{Data sources}

The data used in this study were collected from the Notification System in the City, which had been developed by the local health authority. Characteristics of the City examined in this study included a developed economy (per capita gross domestic product of about $¥ 110000$ ), a high population density (about 20 million people) and an abundance of healthcare resources relative to other areas in China. At each PHI, specific staff members are responsible for entering records of patient complaints into the Notification System. The data of these records include characteristics of the healthcare institution, types of services provided, information about each complaint and reported PVV incidents by hospital level. ${ }^{36}$ In this 1-year study, data from the period between 1 January 2015 and 31 December 2015 were extracted from the system. All personal identifiers (eg, name, employer and contact) were removed, and group-level analyses were carried out.

PHIs with the following characteristics were excluded: (1) institutions with no full-time or part-time staff in charge of entering records into the Notification System and (2) institutions with significant data missing on PVV. After assessment of data quality, a total of 288 PHIs were included in the analysis (figure 1). The location distribution of the 288 PHIs by institutional scale and type is presented in table 1 . In China, hospitals are classified as tertiary hospitals (over 500 ward beds), secondary hospitals (between 100 and 499 ward beds) or primary healthcare facilities (20-99 ward beds). The community healthcare centres are grass-roots PHIs without ward beds. Hospitals are also classified as general hospitals or specialised hospitals. Specialised hospitals include maternal and child hospitals, psychiatric hospitals, cancer hospitals, orthopaedic hospitals, ophthalmology hospitals, geriatric hospitals, infectious disease hospitals and rehabilitation hospitals.

In China, perpetrators tend to commit PVV (also called Yinao ('healthcare disturbance')) against HCWs and/or PHIs, to access more benefit/compensation or to express extreme dissatisfaction with the medical care provided. ${ }^{14-16} 37$ Several previous Chinese studies that have examined the Notification System from the perspective of criminal violence have demonstrated that PVV can be categorised into seven types: (1) the patient or visitor shouts and is verbally abusive in the health institution; (2) the patient or visitor threatens the health institution by writing unpleasant comments on the outside of its walls; (3) the visitor brings the corpse of his or her dead loved one into the hospital and demands compensation; (4) the patient or visitor forcefully occupies a doctor's 


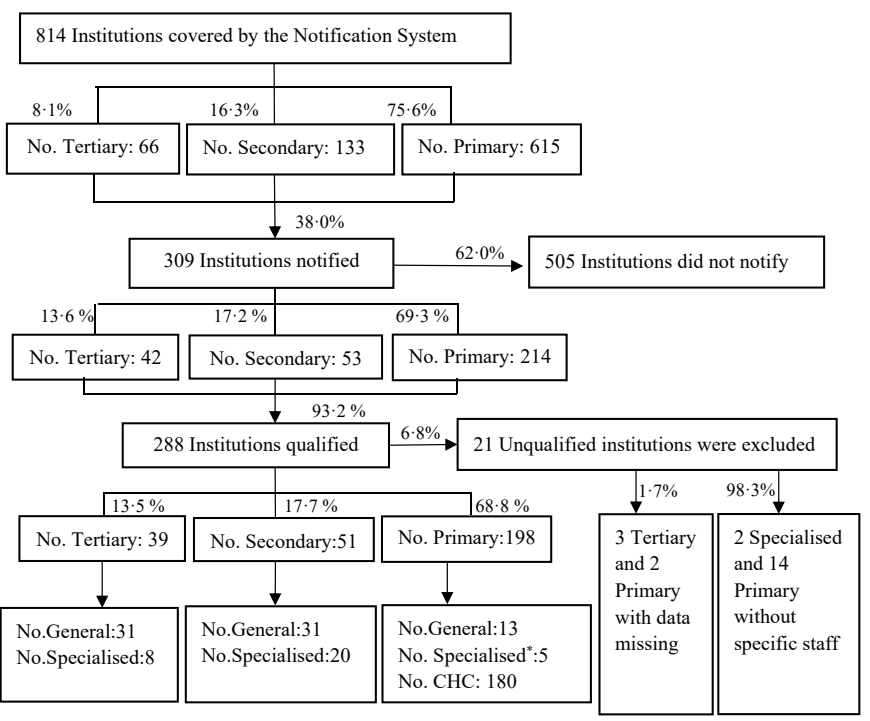

Figure 1 Flow chart of selection of health institutions and healthcare workers (HCW) for this study. *Specialised treatment and prevention institutions (including tuberculosis control centre and mental health treatment and prevention institutions). No.=number of institution. Institution=public healthcare institution. Tertiary=tertiary hospital. Secondary=secondary hospital. Primary=primary healthcare setting. General=general hospital. Specialised=specialised hospital. $\mathrm{CHC}$, community healthcare centre.

office or other key parts of the building for the purpose of threatening HCWs and/or the PHI; (5) the patient or visitor forcefully occupies the ward bed by refusing to go through discharge formality to disturb the normal work of HCWs or destroy medical facilities; (6) the patient or visitor stalks and harasses an HCW inside or outside of working hours; and (7) the patient or visitor attacks an HCW or vandalises the healthcare facilities. However, the seven types of PVV in China do not align directly with internationally recognised forms of workplace violence. For the purpose of comparison with international studies, we combined the seven types of PVV into one category: psychological violence and physical violence. According to HealthWISE, psychological violence is a misuse of power, including the threat of physical force, against another person or group that can result in harm to their physical, mental, spiritual, moral or social well-being (eg, verbal abuse, bullying/mobbing and threats). Physical violence is defined as the use of physical force against another person that results in physical and/or psychological harm (eg, pushing, pinching, beating, kicking, slapping, stabbing, shooting and rape).$^{10}$ Therefore, PVV of types 1-6 is classified as psychological violence, and type 7 is classified as physical violence.

\section{Patient and public involvement}

During the period of data collection of our study, no patient or member of the general public was involved in the design or planning of the study, the selection of outcome measures or the conduct of data collection from the Notification System.

\section{Statistical analysis}

To identify correlations between PVV and workload among HCWs, we defined the incidence rate of PVV and workload of HCWs. The incidence rates of PVV in each group of institutions were calculated as follows: where $i$ is the $i$ th institution, and $i=1,2, \ldots, N$ ( $N=$ the total sample size), $j$ is the $j$ th group (eg, scale, type and location), and $j=0,1,2 \ldots J$ (J)the number of hospital groups). The incidence rates for each institution were calculated when $J$ was 0.

$$
\begin{gathered}
\text { Incidence of } P V V_{j}=\frac{\sum \text { Number of } P V V \text { incidents }_{i j}}{\sum \text { Number of } H C W_{i j}} \times 100 \% \\
\text { Incidence of psychological } P V V_{j}=\frac{\sum \text { Number of psychological } P V \text { incidents } s_{i j}}{\sum{\text { Number of } H C W_{i j}}_{i j}} \times 100 \% \\
\text { Incidence of physical } P V V_{j}=\frac{\sum \text { Number of phssical } P V \text { incident } s_{i j}}{\sum{\text { Number of } H C W_{i j}}_{i j}} \times 100 \%
\end{gathered}
$$

The annual total number of outpatient visits and inpatient admissions was used to estimate HCW workload. In Chinese PHIs, outpatient care is mainly delivered by doctors, whereas inpatient care is jointly delivered by doctors and nurses. Therefore, the indicators of outpatient workload (the average number of daily outpatient visits per doctor) and inpatient workload (the average daily inpatient admissions per doctor or per nurse) were calculated. The workloads of HCWs in each group were calculated as follows: where $i$ is the $i$ th institution, and

Table 1 Location of PHIs by institutional scale and type

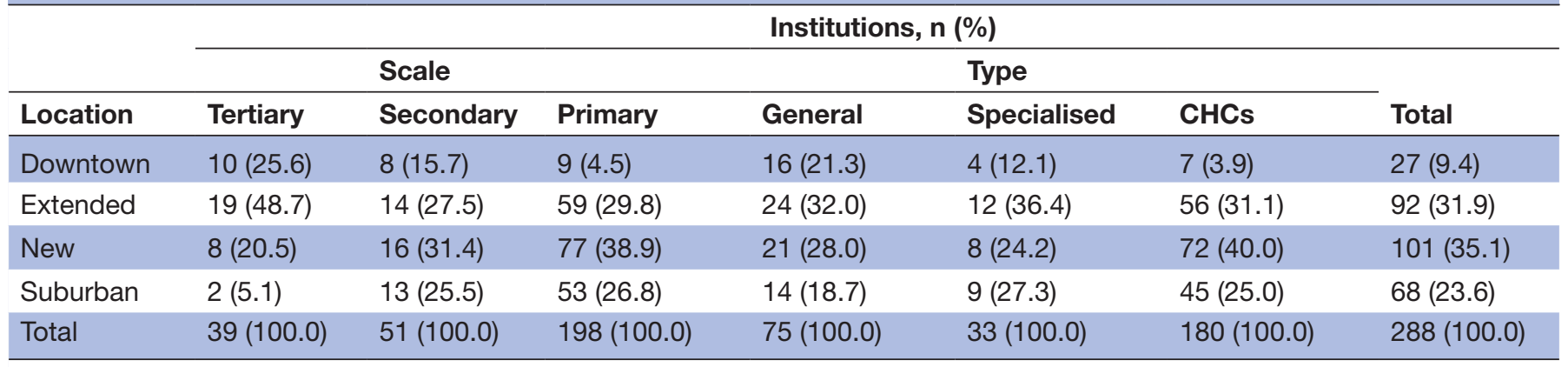

Tertiary=tertiary hospital. Secondary=secondary hospital. Primary=primary healthcare facility. General=general hospital.

Specialised=specialised hospital.

$\mathrm{CHC}$, community healthcare centre; $\mathrm{PHI}$, public health institution. 
$i=1,2, \ldots, N$ ( $N=$ total sample size),$j$ is the $j$ th group (eg, scale, type and location), and $j=0,1,2 \ldots J$ (J=the number of institution groups). The workloads of HCWs for each PHI were calculated when $J$ was 0 .

Outpatient workload $/$ doctor $_{j}=\frac{\sum \text { Number of outpatient visit } s_{i j}}{\sum \text { Number of doctor } s_{i j} \times 249}($ no.of visit $/$ doctor $/$ day $)$

Inpatient workload $/$ doctor $_{j}=\frac{\sum \text { Number of patient admissions } s_{i j}}{\sum \text { Number of doctors } s_{i j} \times 365}($ no. of admission $/$ doctor $/$ day $)$

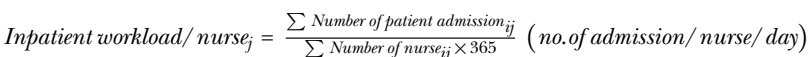

Descriptive statistics were used to identify characteristics of the PHIs. Frequency of PVV events and HCW workload was examined by institutional scale, type and location. In terms of scale, PHIs were categorised as tertiary hospitals, secondary hospitals or primary healthcare facilities (the latter including primary hospitals and community health centres). The PHIs were also categorised by district type: downtown, extended, new and suburban. The highest quality healthcare resources were available in the downtown district. The extended district had a large amount of healthcare resources, but fewer high-quality healthcare resources compared with the downtown district. In the new district, which was in the process of being developed, there were fewer available healthcare resources compared with the extended district. The suburban district is the ecological area of the City. It is a sparsely populated area with relatively few healthcare resources.

In order to determine correlations between HCW workload and the incidence rate of PVV, the $\chi^{2}$ test was used to compare incidence rates of PVV in the different types of hospitals, and Pearson correlation analysis was conducted by institutional scale, type and location, respectively. Then a multiple linear regression model was used to determine the correlation between incidence rate of PVV and HCW workload, while controlling for the effects of scale, type and location. All data analyses were conducted using SPSS V.18.0 software (IBM), and a p value $<0.05$ was considered statistically significant.

\section{RESULTS}

In 2015, a total of 12003 incidents of PVV were recorded at the 288 PHIs with 87998 HCWs in the City. The total number of hospital outpatient visits was 88.9 million in these 288 PHIs, accounting for $1.2 \%$ of outpatient visits nationwide, and inpatient admissions for the 288 PHIs were 1.3 million, accounting for $0.6 \%$ of inpatient visits nationwide. ${ }^{38}$ These facts indicate that the study is a good representation of PHIs in China.

Data on the PHIs, such as number of HCWs, incidence rate of PVV and workload of HCWs, are presented in table 2. The overall incidence rate of PVV for the 288 public healthcare institutions was $13.6 \%$. The incidence rate of psychological PVV was $11.4 \%$, and the incidence rate of physical PVV was $2.2 \%$. In terms of institutional

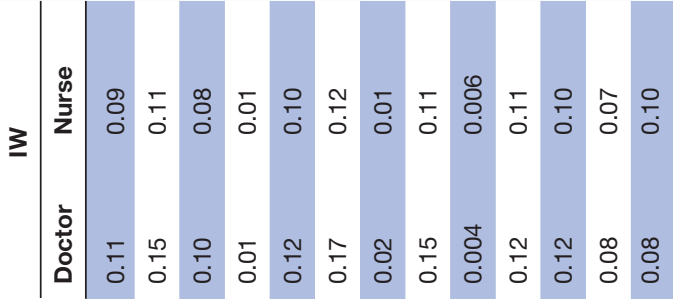

3 3)

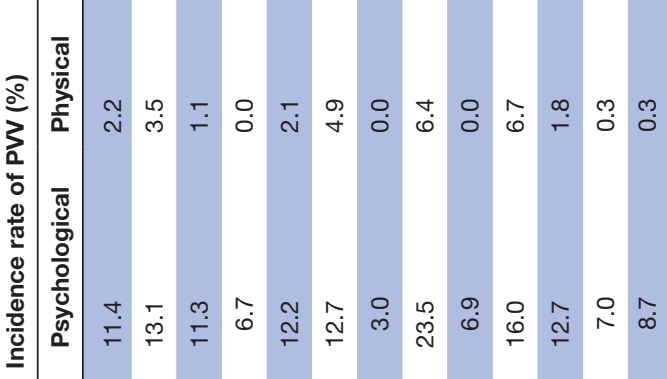

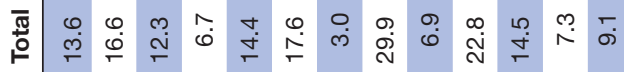
$\sqrt{\frac{.}{0}}$

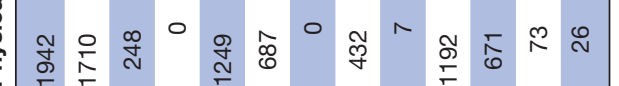

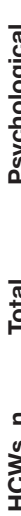

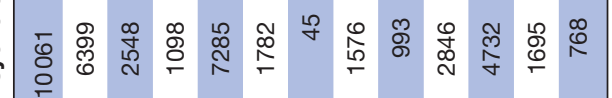
焉

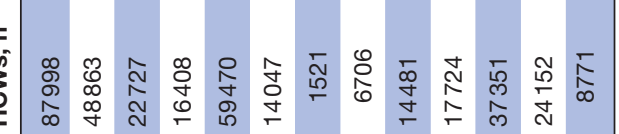

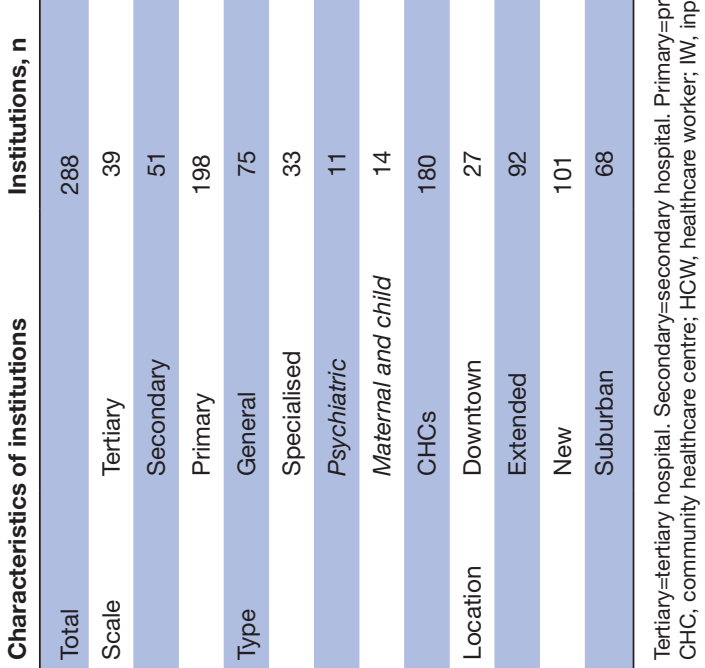


Table 3 Pearson correlation between incidence of PVV and workload of doctor and nurse by institutional scale, type and location

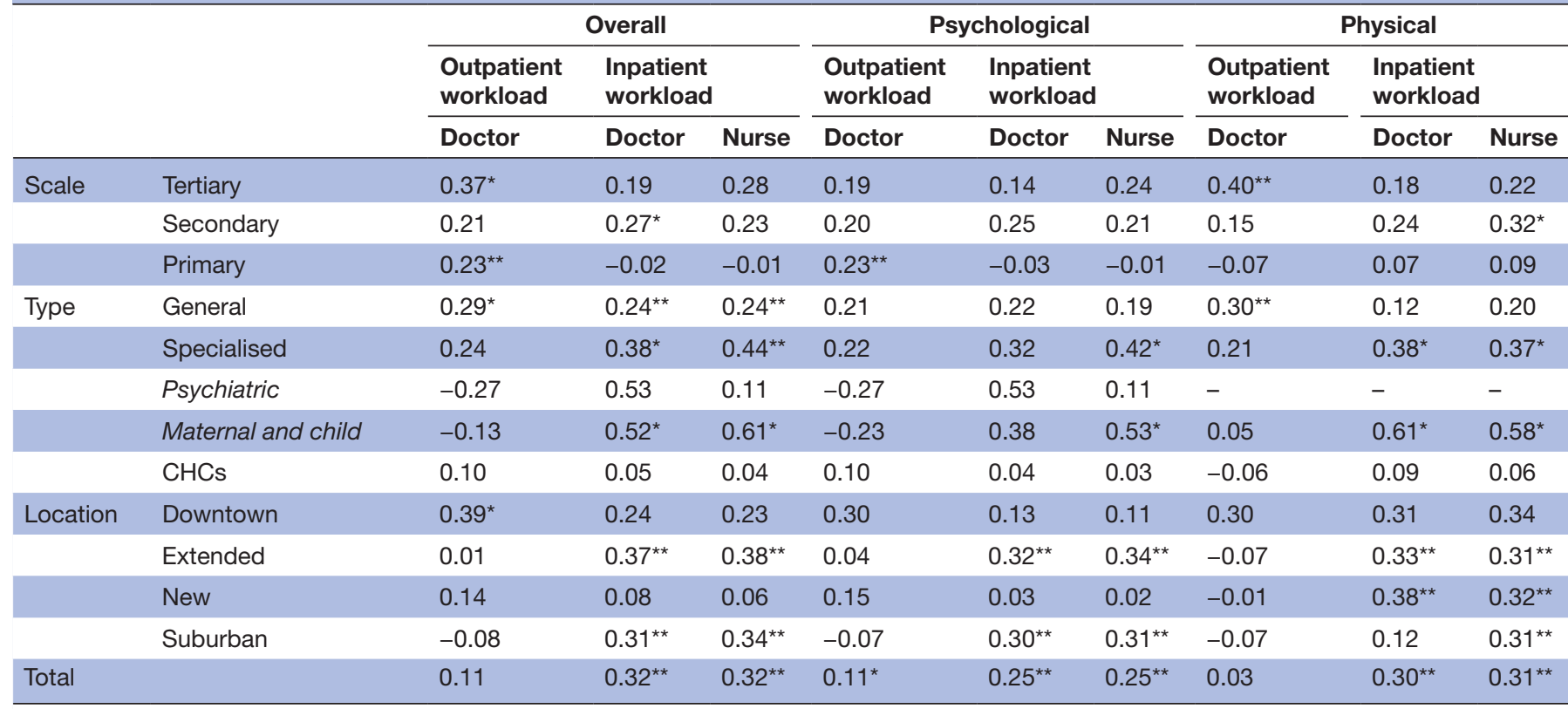

*Significant at $\mathrm{p}<0.05 ;{ }^{* *}$ Significant at $\mathrm{p}<0.01$.

Tertiary=tertiary hospital. Secondary=secondary hospital. Primary=primary healthcare facility. General=general hospital. Specialised=specialised hospital.

$\mathrm{CHC}$, community healthcare centre; PVV, patient and visitor violence.

scale, the incidence rate for tertiary hospitals was highest at $16.6 \%$, which was more than twice that of the primary healthcare settings $(6.7 \%)\left(\mathrm{X}^{2}=1069.3, \mathrm{p}<0.01\right)$. HCWs at tertiary hospitals had the highest inpatient workload (0.15 admissions per doctor per day and 0.11 admissions per nurse per day), which was 15 times higher than that of primary healthcare settings $(F=29.9, \mathrm{p}<0.01)$, with the inpatient workload of doctors somewhat higher than that of nurses. In terms of institutional type, the incidence rate of PVV at specialised hospitals $(17.6 \%)$ was highest $\left(\mathrm{X}^{2}=767.79, \mathrm{p}<0.01\right)$. Specifically, maternal and child hospitals had the highest incidence rate of PVV (29.9\%). The outpatient workload of doctors at maternal and child hospitals was highest (12.2 admissions per doctor per day) among the specialised hospitals. In terms of institutional location, the incidence rate of $\mathrm{PVV}$ in the downtown district was the highest $(22.8 \%)\left(\mathrm{X}^{2}=2254.9, \mathrm{p}<0.01\right)$, and both the workloads of outpatient and inpatient were highest in the downtown district $(F=14.6, \mathrm{p}<0.001)$.

Pearson correlation between incidence of PVV and workload of doctor and nurse by institutional scale, type and location is presented in table 3. The incidence rate of physical PVV in tertiary hospitals correlated positively with the outpatient workload of doctors $(r=0.4, p<0.01)$, and psychological PVV in primary healthcare settings correlated positively with the outpatient workload of doctors $(\mathrm{r}=0.23, \mathrm{p}<0.01)$. The overall incidence rate of PVV for general hospitals correlated positively with both outpatient and inpatient workloads $(\mathrm{p}<0.05)$, whereas the overall incidence rate for specialised hospitals was only positively correlated with inpatient workload. For the maternal and child hospitals, the correlation coefficient between the incidence rate of psychological PVV and inpatient workload of nurses was $0.53(\mathrm{p}<0.05)$, and the correlation coefficient between physical violence and inpatient workload of doctors was $0.61 \quad(p<0.05)$. The overall incidence rate of PVV in the downtown district was positively correlated with outpatient workload $(\mathrm{r}=0.39$, $\mathrm{p}<0.05$ ), and the overall incidence rates of PVV for the extended and suburban districts were both positively correlated with inpatient workload.

Multiple linear regression model results (table 4) showed that after controlling for institution scale, type and location, the overall incidence rate of PVV in PHIs was significantly positively correlated with the outpatient workload of doctors $(\beta=0.236, p<0.01)$, and there was a positive relationship between psychological incidence rate of PVV and outpatient workload of doctors $(\beta=0.186$, $\mathrm{p}<0.05)$.

Of interest, there was a positive correlation between incidence rate of PVV and outpatient workload of doctors. These results indicate that the incidence rate of PVV rose with the incremental increase of outpatient workload per doctor.

\section{DISCUSSION}

\section{The problem of PVV in China}

$\mathrm{PVV}$ in China has received much attention from international organisations and the central government. ${ }^{11} 1214-163739$ However, although PVV is a critical issue for healthcare delivery, information on PVV is 
Table 4 Multiple linear regression analysis results

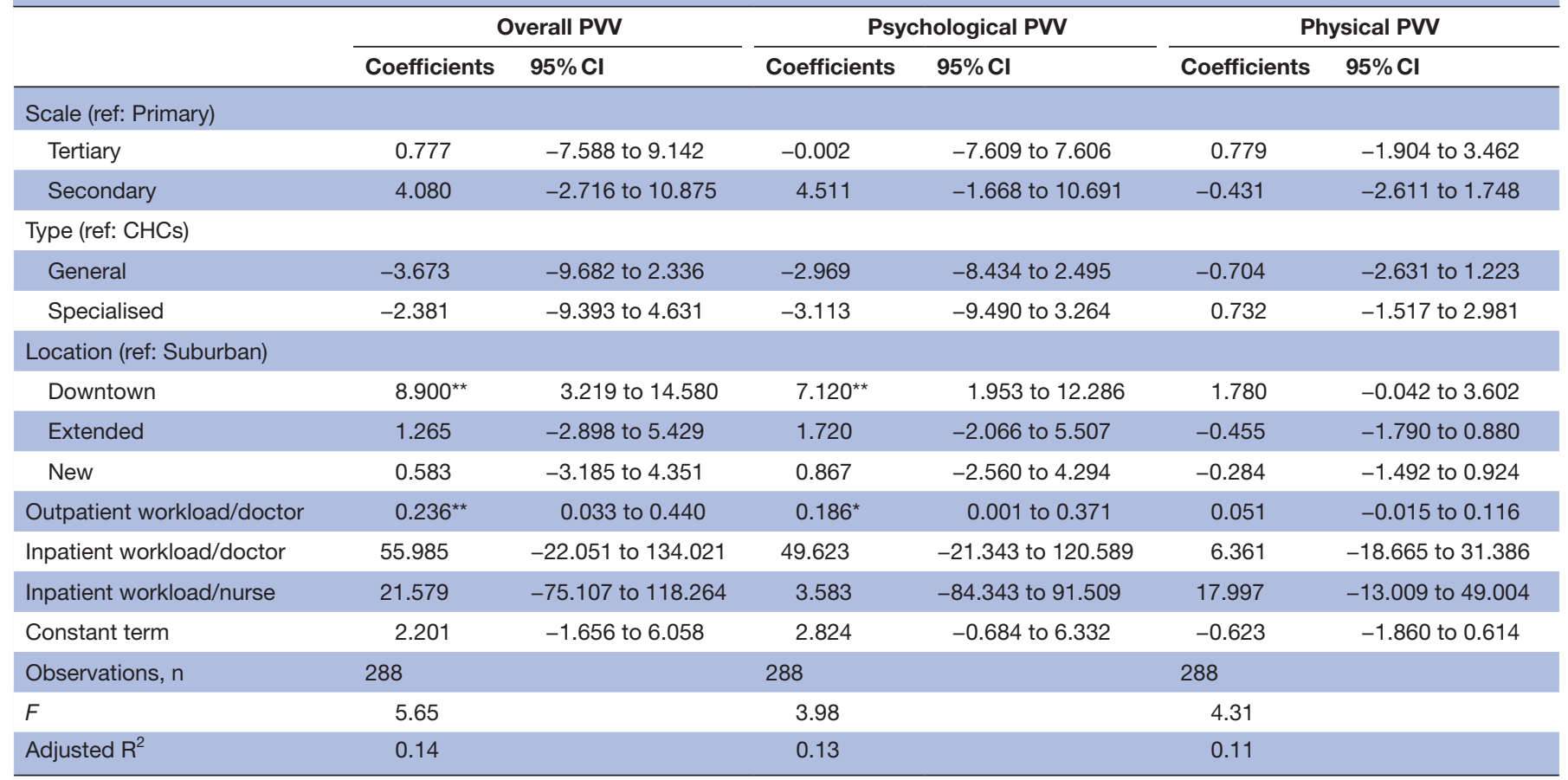

*Significant at $p<0.05 ;{ }^{*}$ Significant at $p<0.01$.

Tertiary=tertiary hospital. Secondary=secondary hospital. Primary=primary healthcare facility. General=general hospital. Specialised=specialised hospital.

$\mathrm{CHC}$, community healthcare centre; PVV, patient and visitor violence.

primarily provided through the media (in extreme cases) and annual report of the Supreme People's Court in China. To our knowledge, this study is the first to report on incidence rates of overall PVV, psychological PVV and physical PVV in the health sector using records on violent incidences in the Notification System. Data from the Notification System indicate that the incidence rate of overall PVV, psychological PVV and physical PVV was $13.6 \%, 11.4 \%$ and $2.2 \%$, respectively. Tertiary PHIs had higher risk of PVV (16.6\%) compared with primary and secondary PHIs. Specialised PHIs had higher risk of PVV $(17.6 \%)$ compared with general hospitals $(14.4 \%)$. The highest incidence rate of PVV in specialist PHIs was at maternal and child hospitals (29.9\%), and the incidence rate of PVV in the downtown district was highest $(22.8 \%)$ among varied institutional locations.

There is currently a three-stage national strategy to prevent PVV in the health sector. ${ }^{18}$ The need to implement comprehensive measures preventing and controlling violence in the health sector is urgent, both from a national and international perspective. Before 2017, nearly every law, regulation, policy, measure and study on violence in China focused on criminal violence. After 2017, some investigators began conducting research on workplace violence. They began using international instruments to measure workplace violence for international comparative indicators, and to provide recommendations for the implementation of workplace hazards prevention and control measures (including the incorporation of antiviolence measures into basic healthcare and health promotion laws). This study sheds light on the situation regarding PVV in the health sector, analysing the problem from the perspective of criminal violence. At the hospital level, specific staff members should be placed in charge of occupational health issues. These staff members should focus on occupational health at all hospital levels (primary, secondary and tertiary hospitals). It is worth noting that there were 505 PHIs with no report of PVV, which indicates that there was little occupational health prevention and control, including violence prevention, at these PHIs.

\section{Understanding the correlation between PVV and HCW workload in the City}

In this study, both overall PVV and psychological PVV appear to be positively significantly associated with outpatient workloads of HCWs in both correlation and regression analyses, while physical PVV was only positively correlated with the inpatient workload of HCWs in correlation analysis. There was no statistically significant positive association between physical PVV and workloads in multiple linear regression. One explanation could be that the number of PHIs with physical PVV (20 PHIs) was too small for multiple linear regression. However, overall PVV was positively associated with outpatient workload. Our findings are directly supported by previous literature that indicates that heavy workloads and healthcare manpower shortages are causally related to violence. ${ }^{30} 40$ These studies suggested a mechanism linking workload and PVV; HCW shortages may cause consequent overextended workloads. Then the occurrence of inadequate communication with patients and their visitors leads 
to more waiting time and lower quality of service than expected, thus increases the risk of PVV towards HCWs.

Our study found that specialised PHIs have higher risk of PVV (17.6\%) compared with general PHIs (14.4\%). This finding has not yet been reported in China, and contradicts those of a Canadian study. ${ }^{9}$ Further analysis indicated that the inpatient workload of HCWs in specialised PHIs was higher than that in general PHIs, and was significantly positively associated with PVV, especially in maternal and child hospitals. One previous study found that HCWs in paediatric departments were at an increased risk of PVV. ${ }^{41}$ It has been reported that there has been a long labour shortage of paediatricians in China, adding to the workload in maternal and child hospitals and making it difficult to meet the needs and expectations of child patients and their family members. ${ }^{42}{ }^{43}$ In addition, patients in maternal and child hospitals are more vulnerable and sensitive than other types of patients, thus increasing the possibility of conflicts and PVV.

PHIs in the downtown district were found to be at significantly higher risk for PVV, which was positively associated with the outpatient workload of doctors. However, other studies have found that the risk for violence is high in rural areas and small-scale healthcare facilities. ${ }^{8}$ Institutions in the downtown and extended districts are more densely populated than other locations in the City. These areas consist of more tertiary and general PHIs as shown in table 1. Our findings suggest that PVV is positively associated with the workload of HCWs in PHIs.

More importantly, according to national statistics, $89.8 \%$ of HCWs believe that their workload has been increasing constantly over the past 5 years. ${ }^{44}$ The nationwide number of outpatient visits and inpatient admissions in Chinese PHIs increased from $97.7 \%$ in 1995 to $389.6 \%$ in 2015, whereas the number of licensed physicians at the same period across China had only increased by $58.5 \%{ }^{43}$

\section{Implications for policymaking}

The Chinese government has made great efforts to reduce violence in the health sector. The Measures for the Complaints Management in Medical Institutions was issued in 2019 by the National Health Commission, making complaint handling systems mandatory. The system must be managed by full-time or part-time staff in a designated department. ${ }^{45}$ Our study will provide new empirical evidence for implementation of the measures.

In a national campaign, entitled Security Hospital Establishment, PHIs were encouraged to provide several support services to HCWs, including training on communicating with patients and essential knowledge regarding security protection, buying medical liability insurance, installing security alarm systems, establishing police stations in the hospital and strengthening security in the hospital. ${ }^{24}$ However, current PVV policies in China mainly focus on physical violence, especially extreme crimes. ${ }^{46}$ This is primarily a reactive approach, and not a proactive one. Scientific research, ${ }^{47}$ best practices and international guidelines $^{23}$ suggest that clear definitions of workplace violence are needed to develop guidance based on rights and responsibilities, to better monitor and assess PVV and to perform workplace interventions. In general, PVV prevention should be an integrated part of occupational health and safety management systems in the health sector. For instance, in the nationwide implementation of HealthWISE, which began in 2013, violence has been included among the occupational hazards of the health sector, the managerial system is value added. ${ }^{48}$ Interventions for preventing violence can be conducted at the hospital level. ${ }^{49}$

Furthermore, the rise in workload among HCWs may be due, in part, to organisational structure. The doctors and nurses who visit the greatest number of patients will be subjected to more aggressive workplace violence. Hospitals tend to provide more confined healthcare services, whereas community-based primary care services are more dispersed. The solution may be the establishment of a tiered healthcare delivery system in which primary healthcare and hospital care can be coordinated. There has been past evidence of this in recent years in China. ${ }^{39}$ Patient complaint records in the Notification System could be modified to include more detailed information about PVV, and gradually expanded to include HCW reports, aligning these with internationally recognised forms of PVV (or occupational violence). The Notification System could be an even better source of PVV information to guide further strategic and targeted intervention. ${ }^{18} 19$

Around the time this article was written, an emergency physician at Beijing's Civil Aviation General Hospital was fatally stabbed by a patient's son. Recently, the Chinese government passed the Law of the People's Republic of China on Basic Health Care and Health Promotion, which forbids threats or harms to the personal safety and dignity of HCWs by any institution or individual. ${ }^{50}$ However, violence against HCWs in China will not be halted through law enforcement and punitive measures alone, and the comprehensive measures discussed above are critical to the law's effectiveness.

\section{Strengths and limitations of the study}

To our knowledge, ours is the first study to investigate PVV incidence rates in Chinese PHIs from the perspective of criminal violence using big data. A multiple linear regression model was used to determine the correlations between HCW workload and the incidence rate of PVV, while controlling for the effect of scale, type and location. Therefore, this study provided solid evidence to guide future PVV intervention.

This study had several limitations related to data availability and quality. Data used in this study originated from the Notification System, which was not intentionally designed for investigation of workplace violence, but for criminal violence. In addition, domestic data on violence are defined differently from international data. Therefore, the incidence rates of PVV in this study reflected relatively extreme workplace violence. Future research should focus on more specific risks in tertiary hospitals 
and specialised hospitals, especially the risk in maternal and child hospitals, which had the highest rates of PVV and highest burden of workload.

\section{CONCLUSIONS}

Chinese PHIs and their HCWs face significant challenges related to PVV. The findings of this study are reliable and provide an understanding of PVV risk in China from the perspective of criminal violence. Heavy workloads among HCWs contribute significantly to the growing risk of PVV. More attention should be paid to the workload of HCWs in tertiary and specialised hospitals and in institutions located in downtown districts. The monitoring and prevention of PVV should be an integral part of the occupational health and safety management system; commitment at the highest level is critical. The Notification System also needs to be improved and can be employed in future interventions that target PVV.

Acknowledgements The authors thank Thomas H Gassert, MD (TH Chan School of Public Health of Harvard University) for assistance with the editing of their manuscript.

Contributors MZ conceived and designed the study and modified the manuscript. $\mathrm{XL}$ conducted surveillance, collected data and had full access to all of the data in the study. JH conducted the literature search, performed the data analysis, interpreted the data and wrote the first draft. All authors made important contributions to subsequent drafts and have seen and approved the final version. All authors had full access to all the data in the study and can take responsibility for the integrity of the data and the accuracy of the data analysis.

Funding This research was supported by the Chinese Association of STD and AIDS Prevention and Control and the ILO cooperation project: HealthWISE TOT Workshop (2017-GA-03/CHN179).

Disclaimer The funder had no influence on the study design; on the collection, analysis and interpretation of data; on the writing of the report; or on the decision to submit the article for publication.

Competing interests None declared.

Patient and public involvement Patients and/or the public were not involved in the design, or conduct, or reporting, or dissemination plans of this research.

Patient consent for publication Not required.

Ethics approval This study was automatically approved by the Ethical Review Committee of the Chinese Academy of Medical Sciences according to internal regulations. All personal identifiers (name, employer, contact) were removed from the data set, and analyses were carried out at the institution level.

Provenance and peer review Not commissioned; externally peer reviewed.

Data availability statement Data are available upon reasonable request. All data relevant to the study are included in the article or uploaded as supplementary information. The data supporting the conclusion of this article are included in the article. No additional data available. The data sets used and analysed during the current study are available from the corresponding author on reasonable request.

Open access This is an open access article distributed in accordance with the Creative Commons Attribution Non Commercial (CC BY-NC 4.0) license, which permits others to distribute, remix, adapt, build upon this work non-commercially, and license their derivative works on different terms, provided the original work is properly cited, appropriate credit is given, any changes made indicated, and the use is non-commercial. See: http://creativecommons.org/licenses/by-nc/4.0/.

ORCID iD

Ju Huang http://orcid.org/0000-0002-7810-4550

\section{REFERENCES}

1 The International Council of Nurses (ICN), the World Health Organization (WHO), Public Services International (PSI), the International Labour Organization (ILO). Framework guidelines for addressing workplace violence in the health sector, 2002. Available: http://www.who.int/violence injury prevention/violence/activities/ workplace/en/ [Accessed 15 Apr 2019].

2 Schablon A, Wendeler D, Kozak A, et al. Prevalence and consequences of aggression and violence towards nursing and care staff in Germany-A survey. Int $J$ Environ Res Public Health 2018;15:1274-92.

3 Zhan Y, Kim SK, Zhou L, et al. Patient violence and health professionals' occupational outcomes in China: a time-lagged survey study. Int J Nurs Stud 2019;94:120-30.

4 Akbolat M, Sezer C, Ünal Özgün, et al. The effects of direct violence and witnessed violence on the future fear of violence and turnover intention: a study of health employees. Curr Psychol 2019;27:1-7.

5 Occupational Safety and Health Administration (OSHA). Guidelines for preventing workplace violence for healthcare and social services workers, 2015. Available: https://www.osha.gov/Publications/ osha3148.pdf [Accessed 20 June 2016].

6 PSI, WHO, ICN, ILO. Framework guidelines for addressing workplace violence in the health sector: the training manual. Switzerland: ILO publications, 2005

7 Liu J, Gan Y, Jiang H, et al. Prevalence of workplace violence against healthcare workers: a systematic review and meta-analysis. Occup Environ Med 2019;76:927-37.

8 Carmi-Iluz T, Peleg R, Freud T, et al. Verbal and physical violence towards hospital- and community-based physicians in the Negev: an observational study. BMC Health Serv Res 2005;5:1-6.

9 Hahn S, Zeller A, Needham I, et al. Patient and visitor violence in general hospitals: a systematic review of the literature. Aggress Violent Behav 2008;13:431-41.

10 Mishra S, Chopra D, Jauhari N, et al. Violence against health care workers: a provider's (staff nurse) perspective. Int J Community Med Public Health 2018;5:4140-8.

11 Chinese doctors are under threat. Lancet 2010;376:657.

12 Violence against doctors: why China? why now? what next? Lancet 2014;383:1013.

13 Li Z, Yan C-M, Shi L, et al. Workplace violence against medical staff of Chinese children's hospitals: a cross-sectional study. PLoS One 2017;12:e0179373.

14 Zhang L, Stone TE, Zhang J. Understanding the rise of Yinao in China: a commentary on the little known phenomenon of healthcare violence. Nurs Health Sci 2017;19:183-7.

15 Pan Y, Yang Xhong, He JP, et al. To be or not to be a doctor, that is the question: a review of serious incidents of violence against doctors in China from 2003-2013. J Public Health 2015;23:111-6.

16 Peng W, Ding G, Tang Q, Wei P, Gan D, Qi T, et al. Continuing violence against medical personnel in China: a flagrant violation of Chinese law. Biosci Trends 2016;10:240-3.

17 Jiao M, Ning N, Li Y, et al. Workplace violence against nurses in Chinese hospitals: a cross-sectional survey. BMJ Open 2015;5:e006719.

18 Zhang M. How to implement workplace violence prevention and control at hospital level? Chin Nurs Res 2019;19:481-7.

19 Zhang M. International consensus on workplace violence in health sector and its meaning to practice in China. Chin Nurs Res 2019;19:923-8.

20 Chen , N, Zhang, M, Li R. Investigation on workplace violence in a grade $2 \mathrm{~A}$ hospital $-\mathrm{A}$ survey using the investing tool for workplace violence in hospitals developed by the world Health organization. Chin Med J 2019;46:157-62.

21 Sun P, Zhang X, Sun Y, Peihang S, Yihua S, et al. Workplace violence against health care workers in North Chinese hospitals: a crosssectional survey. Int J Environ Res Public Health 2017;14:96.

22 ILO. Ending violence and harassment against women and men in the world of work. Geneva, 2018.

23 ILO. Concerning the elimination of violence and harassment in the world of work, 2019.

24 National Health and Family Planning Commission of P. R. of China. Notification on the progress for assurance of medical service order in 2016. Available: http://www.moh.gov.cn/yzygj/s3590/201702/ de9f284c30f546dba85ba8323538cfa8.shtml [Accessed 2 Dec 2017].

25 International Labour Office (ILO), World Health Organization (WHO). HealthWISE-Action manual. work improvement in health services. Beijing: Science Press, 2016.

26 Gatchel RJ. The importance of the profession of nursing in health care: current and future issues. J Appl Biobehav Res 2018;23:e12127. 
27 Hahn S, Müller M, Hantikainen V, et al. Risk factors associated with patient and visitor violence in general hospitals: results of a multiple regression analysis. Int J Nurs Stud 2013;50:374-85

28 Kling RN, Yassi A, Smailes E, et al. Characterizing violence in health care in British Columbia. J Adv Nurs 2009;65:1655-63.

29 Mei X, Guoti H, Gao XJ. Causal factor analysis of violence to health workers and its strategy. J Clin Hypertens 2014;1:191.

30 Privitera MR. Organizational contributions to healthcare worker (HCW) burnout and workplace violence (WPV) overlap: is this an opportunity to sustain prevention of both? Health 2016;08:531-7.

31 Schablon A, Zeh A, Wendeler D, et al. Frequency and consequences of violence and aggression towards employees in the German healthcare and welfare system: a cross-sectional study. BMJ Open 2012;2:e001420.

32 Sun $\mathrm{P}$, Zhang X, Sun Y, et al. Workplace violence against health care workers in North Chinese hospitals: a cross-sectional survey. Int J Environ Res Public Health 2017;14:96.

33 Lin Y-H, Liu H-E, YuHua L, HsuehErh L. The impact of workplace violence on nurses in South Taiwan. Int J Nurs Stud 2005;42:773-8.

34 Xu W, Xie J, Wu H. The Association between Chinese Doctor's Workload and Medical Disputes. J Psychol Psychother 2016;06.

35 Juan W, Rui Y, Xueqing Z, et al. Construction of hospital medical complaint management system. J Qiqihar Univ Med 2015;36:3229-31.

36 Wei C, Xin L. Guidelines for hospital complaints management. Beijing: People's Military Medical Press, 2013.

37 Hesketh T, Wu D, Mao L, et al. Violence against doctors in China. BMJ 2012;345:e5730.

38 National Health and Family Planning Commission. Statistical yearbook for health and family planning in China 2016. Beijing: Peking Union Medical College press, 2016.

39 The Lancet .A tiered health-care delivery system for China. Lancet 2019;393:1178.
40 YaFei Z, SuiShu J. Qualitative analysis of the nurses' cognition on causes of the workplace violence. Chin J Nurs 2016:51:1335-9.

41 Yassi A, Annalee Y. Assault and abuse of health care workers in a large teaching hospital. CMAJ 1994;151:1273-9.

42 National Health and Family Planning Commission. Statistical Yearbook for health and family planning in China, 2017. Beijing: Peking Union Medical College press, 2017.

43 Qiuxia S, Fang W, Li S, et al. The pediatrician demands and gaps under the universal two-child policy. Chin J Health Policy 2016;9:65-70.

44 Center for Statistics and Information, National Health and Family Planning Commission. China health manpower development report (2010-2016). Beijing: Peking Union Medical College press, 2017.

45 National Health and Family Planning Commission. Notification on the progress for assurance of medical service order in 2016, 2017. Available: http://www.moh.gov.cn/yzygj/s3590/201702/de9f284 c30f 546dba85ba8323538cfa8.shtml

46 Tuo L, Min Z, Lihui X. Systematic analysis on legal system of workplace violence prevention and control in Chinese medical institutions. Chin Med J 2017;44:290-6.

47 Berlanda S, Pedrazza M, Fraizzoli M, et al. Addressing risks of violence against healthcare staff in emergency departments: the effects of job satisfaction and attachment style. Biomed Res Int 2019;2019:1-12.

48 Min Z, Lihui X, Tuo L. Model of hospital initiative on systematic occupational health: from advocacy to practice of health protection for healthcare workers. Chin J Nurs Manag 2018;18:145-9.

49 Baig LA, Shaikh S, Polkowski M, et al. Violence against health care providers: a mixed-methods study from Karachi, Pakistan. J Emerg Med 2018;54:558-66.

50 The Lancet. Protecting Chinese doctors. Lancet 2020;395:90. 